Dikirim: 13 Juni 2016 Diterbitkan: 1 Maret 2017

\section{Pengetahuan tentang manajemen program pada mahasiswa fakultas kesehatan masyarakat Universitas Sam Ratulangi Manado}

\author{
Managerial knowledge among public health students in Sam \\ Ratulangi University from Manado
}

Novi Inriyanny Suwendro ${ }^{1}$, Mubasysyir Hasanbasri ${ }^{2}$, Rossi Sanusi ${ }^{2}$

\section{Abstract}

Purpose: This study aimed to identify the knowledge about management and its relation with individual characteristics, face-to-face courses, and field study experiences. Methods: This research was an observational study using a cross-sectional design. The subjects were all last grade Public Health students of Sam Ratulangi University. A questionnaire was used as the research instrument. The independent variables were the individual characteristics and learning process, and the dependent variable was the students' managerial knowledge. The data analysis used chi-square and multiple logistic regression tests. Results: The respondents were 206 students (61.13\%). Students with a good knowledge about management were $48.54 \%$. The significant determinants in individual level about students' managerial knowledge were students' satisfaction about lectures (OR: 2.1), parents' occupation (OR: 2.9) and their desired position in the future (OR: 0.5). The face-to-face courses and field learning experience were not correlated with managerial knowledge. Conclusion: There was some variation in students' knowledge about the practice of managerial function. The managerial knowledge function has positive correlation with the satisfaction about lectures and parents' occupation, but has a negative correlation with the intention to work in the Ministry of Health. Students who intended to work in the Ministry of Health have worse knowledge than those who did not intend to. Face-to-face courses and field study experience were not correlated with students' managerial knowledge.

Keywords: managerial competence; managerial function; learning process; public health faculty

\footnotetext{
${ }^{1}$ Departemen Kebijakan dan Manajemen Kesehatan, Fakultas Kedokteran, Universitas Gadjah Mada

(Email: novi_inriyanny@mail.ugm.ac.id)

${ }^{2}$ Departemen Biostatistik, Epidemiologi dan Kesehatan Populasi, Fakultas Kedokteran, Universitas Gadjah Mada
} 


\section{PENDAHULUAN}

Lulusan program pendidikan sarjana kesehatan masyarakat paling penting untuk mendukung efektivitas program-program dinas kesehatan di masyarakat. Meskipun demikian penelitian tentang apakah mahasiswa memperoleh pengetahuan dan keterampilan manajeman program ketika mereka duduk di perguruan tinggi sangat terbatas. Penelitian ini merupakan salah satu upaya untuk melihat apakah calon lulusan perguruan tinggi kesehatan masyarakat memiliki pengetahuan dan ketrampilan manajemen yang memadai untuk bisa bekerja dan meningkatkan kinerja mereka ketika berkarir di dinas kesehatan. Penelitian tentang pengetahuan dan kompetensi manajemen telah banyak memusatkan diri pada mereka yang sudah bekerja di setting tempat kerja terkait pengetahuan dan kompetensi manajerial.

Keberhasilan program kesehatan tergantung pada efektivitas manajemen (1,2). Sistem kesehatan di seluruh dunia termasuk Indonesia masih menghadapi masalah keterbatasan manajer yang berkompeten di semua tingkatan. Layanan kesehatan tidak mencapai sasaran karena kompetensi manajemen di semua level masih rendah (1-3). Proses manajerial puskesmas dan rumah sakit masih perlu ditingkatkan (4-7).

Masalah dalam sistem kesehatan saat ini berupa kekurangan penempatan tenaga sesuai keahlian (1). Fasilitas-fasilitas layanan kesehatan di Indonesia masih menempatkan tenaga klinis pada posisi manajerial (8). Tenaga klinis kurang efektif dalam menjalankan fungsi manajemen (6-9). Sebaiknya, manajer diperankan oleh tenaga yang berkompeten di bidang manajemen kesehatan masyarakat (10).

Manajer memiliki peran yang unik dan kompleks (9). Teori mengenai peran manajer, keterampilan manajerial dan kompetensi manajerial sudah banyak $(2,11)$. Kompetensi dasar yang wajib dikuasai oleh manajer adalah tentang fungsi manajemen yang terdiri dari planning organizing, actuating, controlling dan evaluating yang disingkat POACE (12).

Kompetensi manajerial dari manajer dipengaruhi pendidikan dan pelatihan yang diterima $(6,13,14,15)$. Perguruan tinggi sangat berperan dalam meningkatkan wawasan dan keterampilan $(15,16)$. Kepedulian tentang kompetensi manajemen belum mendapat perhatian yang besar dalam penyusunan kurikulum di perguruan tinggi $(17,8,19)$. Terdapat gap tentang domain pengetahuan manajemen yang diharapkan dan yang diperoleh mahasiswa melalui pendidikan formal di universitas $(15,19)$.
Fakultas Kesehatan Masyarakat Universitas Sam Ratulangi memiliki peran strategis dalam penyediaan manajer kesehatan di Sulawesi Utara. Perhatian kurang terhadap penempatan manajemen dalam kurikulum pendidikan tinggi yang ditandai dengan adanya gap pengetahuan manajemen dalam penelitian terdahulu (18,19), maka dianggap perlu untuk meneliti pengetahuan manajemen pada mahasiswa Fakultas Kesehatan Masyarakat Universitas Sam Ratulangi Manado. Penelitian ini bertujuan menjawab pertanyaan apakah mahasiswa fakultas kesehatan masyarakat yang di masa akan datang memiliki pendidikan yang memadai dalam hal pengetahuan dan kompetensi manajerial agar mereka bisa bekerja menjadi manajer program-program public health di dinas kesehatan, tempat mereka akan paling besar kemungkinan bekerja.

\section{METODE}

Penelitian ini menganalisis 206 orang mahasiswa tahun keempat yang bersedia menjadi responden, 61\% dari total 337 mahasiswa tahun keempat angkatan tahun 2011 di Fakultas Kesehatan Masyarakat Universitas Sam Ratulangi. Pengetahuan tentang fungsi manajerial diukur menggunakan kuesioner yang dibuat berdasakan kebutuhan peneliti dengan 14 pertanyaan tentang kegiatan-kegiatan terkait manajemen program yang diasumsikan ditemukan dalam praktik manajemen, yang berbasis pada unsur persiapan, organizing, actuating, controlling, dan evaluating yang kemudian divalidasi.

Analisis data dilakukan menggunakan uji chi-square dan regresi logistik dengan bantuan aplikasi pengolah data dan statistik STATA 12. Penelitian ini telah mendapat keterangan kelayakan etik dari Komite Etik Penelitian Kedokteran dan Kesehatan Fakultas Kedokteran Universitas Gadjah Mada.

\section{HASIL}

Tabel 1 menunjukkan ranking pengetahuan tentang fungsi manajemen. Pengetahuan mahasiswa yang paling baik adalah terkait fungsi pengawasan, melakukan supervisi kegiatan (73,3\%) sedangkan peringkat terendah adalah terkait fungsi perencanaan tentang menghitung biaya yang tersedia (24,8\%). Distribusi pengetahuan tentang lima fungsi manajemen sangat beragam, untuk setiap pertanyaan terkait satu fungsi manajemen menempati peringkat yang berbeda-beda dengan perbedaan yang cukup signifikan. Misalnya untuk fungsi perencanaan diwakili 4 
pertanyaan, dua pertanyaan menempati peringkat teratas yaitu peringkat ke 2 dan 4 sedangkan dua pertanyaan lain menempati peringkat terbawah yaitu 11 dan 14. Hal yang sama terjadi untuk fungsi manajemen yang lain kecuali fungsi pengawasan karena hanya diwakili oleh satu pertanyaan.

Tabel 1. Ranking persentase mahasiswa yang menjawab benar tentang pengetahuan manajemen

\begin{tabular}{|c|c|c|c|}
\hline Pengetahuan Fungsi Manajemen & $\begin{array}{c}\mathbf{n} \\
\text { Benar }\end{array}$ & $\%$ & Rank \\
\hline Melakukan supervisi kegiatan & 151 & 73,3 & 1 \\
\hline Membuat prioritas masalah & 144 & 69,9 & 2 \\
\hline $\begin{array}{l}\text { Membagi tugas dalam pelaksanaan } \\
\text { kegiatan }\end{array}$ & 129 & 62,6 & 3 \\
\hline Menetapkan sasaran dari program & 124 & 60,2 & 4 \\
\hline $\begin{array}{l}\text { Membuat catatan tentang hal-hal } \\
\text { yang masih perlu diperbaiki untuk } \\
\text { program yang akan datang }\end{array}$ & 120 & 58,3 & 5 \\
\hline $\begin{array}{l}\text { Menguraikan tupoksi bagi } \\
\text { masing-masing pelaksana kegiatan }\end{array}$ & 115 & 55,8 & 6 \\
\hline $\begin{array}{l}\text { Mendahulukan layanan bagi ibu } \\
\text { yang memiliki balita }\end{array}$ & 114 & 55,3 & 7 \\
\hline $\begin{array}{l}\text { Menempatkan seseorang pada } \\
\text { posisi yang tepat }\end{array}$ & 113 & 54,9 & 8 \\
\hline $\begin{array}{l}\text { Membuat pasien tidak menunggu } \\
\text { lama }\end{array}$ & 104 & 50,5 & 9 \\
\hline $\begin{array}{l}\text { Setiap peserta penyuluhan diberi } \\
\text { kesempatan untuk bertanya }\end{array}$ & 93 & 45,1 & 10 \\
\hline Membuat indikator keberhasilan & 83 & 40,3 & 11 \\
\hline Membuat laporan kegiatan & 78 & 37,9 & 12 \\
\hline $\begin{array}{l}\text { Meminta peserta program untuk } \\
\text { antri dalam pelayanan }\end{array}$ & 70 & 34,0 & 13 \\
\hline Menghitung biaya yang tersedia & 51 & 24,8 & 14 \\
\hline
\end{tabular}

Tabel 2 menunjukkan mahasiswa yang memiliki pengetahuan baik tentang manajemen 48,54\%.

Tabel 2. Pengetahuan mahasiswa tentang fungsi manajemen

\begin{tabular}{lc}
\hline Pengetahuan tentang Fungsi Manajemen & $\mathbf{\%}$ \\
\hline Baik (> skor rata-rata) & 48,54 \\
Kurang ( $\leq$ skor rata-rata) & 51,46 \\
Total & 100 \\
\hline
\end{tabular}

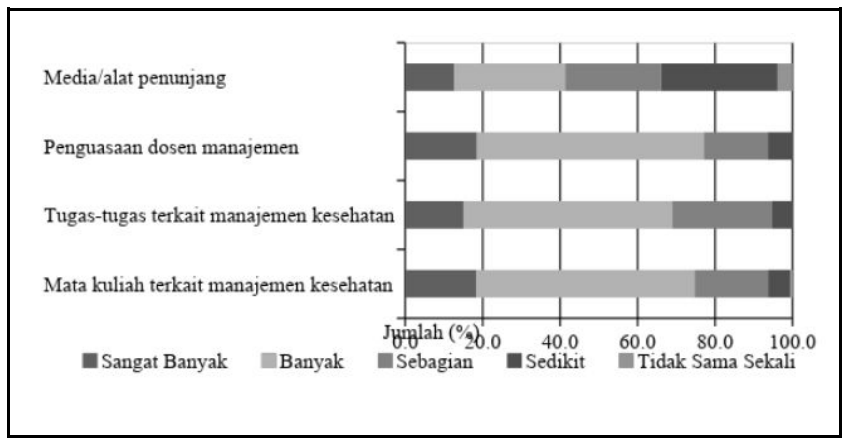

Gambar 1. Kuliah tatap muka di Fakultas Kesehatan Masyarakat Universitas Sam Ratulangi

Gambar 1 menunjukkan proses pembelajaran. Kegiatan kunjungan lapangan telah dilakukan pada berbagai instansi, kecuali kunjungan ke rumah sakit keagamaan dan sosial, lembaga sosial masyarakat kesehatan klinik swasta masih jarang bahkan belum pernah dilakukan sama sekali.

Tabel 3 menunjukkan variabel bebas yang memiliki hubungan dengan pengetahuan manajemen adalah jabatan yang diharapkan dan kepuasan mahasiswa terhadap perkuliahan.

Tabel 3. Pengetahuan manajemen menurut faktor individu dan proses pembelajaran

\begin{tabular}{|c|c|c|c|}
\hline \multirow{2}{*}{ Variabel Bebas } & \multicolumn{2}{|c|}{ Pengetahuan POACE } & \multirow{2}{*}{$\begin{array}{c}\text { OR } \\
(95 \% \mathrm{Cl})\end{array}$} \\
\hline & Baik (n) & Kurang (n) & \\
\hline \multicolumn{4}{|l|}{ Bidang minat } \\
\hline AKK & 28 & 20 & 1,67 \\
\hline Non AKK & 72 & 86 & $(0,83-3,41)$ \\
\hline \multicolumn{4}{|l|}{ Jenis kelamin } \\
\hline Laki-laki & 25 & 35 & 0,67 \\
\hline Perempuan & 75 & 71 & $(0,35-1,29)$ \\
\hline \multicolumn{4}{|c|}{ Pekerjaan orang tua } \\
\hline Tenaga kesehatan & 13 & 6 & 2,49 \\
\hline Non tenaga & 87 & 100 & $(0,84-8,31)$ \\
\hline \multicolumn{4}{|l|}{ kesehatan } \\
\hline \multicolumn{4}{|c|}{ Pilihan masuk FKM Unsrat } \\
\hline \multirow{2}{*}{ Pertama } & 42 & 39 & 1,51 \\
\hline & 36 & 36 & $(0,71-3,25)$ \\
\hline \multirow[t]{2}{*}{ Kedua } & & & 1,40 \\
\hline & 22 & 31 & $(0,65-3,07)$ \\
\hline \multicolumn{3}{|l|}{ Lebih dari dua } & Ref \\
\hline \multicolumn{4}{|c|}{ Alasan memilih masuk FKM } \\
\hline Keinginan pribadi & 58 & 60 & 1,06 \\
\hline Lainnya & 42 & 46 & $(0,59-1,91)$ \\
\hline \multicolumn{4}{|c|}{ Alasan memilih bidang minat } \\
\hline Keinginan pribadi & 85 & 87 & 1,24 \\
\hline & 15 & 19 & $(0,55-2,80)$ \\
\hline \multicolumn{4}{|l|}{ Biaya kuliah } \\
\hline Orang tua & 87 & 97 & 0,62 \\
\hline Beasiswa & 13 & 9 & $(0,22-1,66)$ \\
\hline \multicolumn{4}{|c|}{ Tempat kerja yang diharapkan } \\
\hline Puskesmas & 11 & 17 & $\begin{array}{c}0,60 \\
(0,23-1,55)\end{array}$ \\
\hline Dinas kesehatan & 42 & 45 & $\begin{array}{c}0,87 \\
(0,47-1,64)\end{array}$ \\
\hline Lainnya & 47 & 44 & Ref \\
\hline \multicolumn{4}{|c|}{ Jabatan yang diharapkan } \\
\hline Kepala dinas & 27 & 43 & 0,42 \\
\hline kesehatan & & & $(0,18-0,96)^{*}$ \\
\hline Kepala puskesmas & 19 & 23 & $\begin{array}{c}0,55 \\
(0,22-1,40)\end{array}$ \\
\hline $\begin{array}{l}\text { Koordinator } \\
\text { program }\end{array}$ & 27 & 22 & $\begin{array}{c}0,82 \\
(0,33-2,01)\end{array}$ \\
\hline Lainnya & 27 & 18 & Ref \\
\hline \multicolumn{4}{|c|}{ Kesediaan bekerja di daerah terpencil } \\
\hline Bersedia & 69 & 69 & 1,19 \\
\hline Tidak bersedia & 31 & 37 & $(0,64-2,23)$ \\
\hline \multicolumn{4}{|c|}{ Keinginan melanjutkan studi } \\
\hline Ya & 81 & 83 & 1,18 \\
\hline Tidak & 19 & 23 & $(0,57-2,48)$ \\
\hline \multicolumn{4}{|c|}{ Kepuasan terhadap perkuliahan } \\
\hline Puas & 62 & 49 & 1,89 \\
\hline Kurang puas & 38 & 57 & $(1,05-3,44)^{*}$ \\
\hline \multicolumn{4}{|c|}{ Kunjungan lapangan } \\
\hline Banyak & 32 & 49 & 0,64 \\
\hline \multirow{2}{*}{\multicolumn{4}{|c|}{ Kuliah tatap muka }} \\
\hline & & & \\
\hline Baik & 38 & 54 & 0,66 \\
\hline Kurang & 62 & 52 & $(0,36-1,19)$ \\
\hline
\end{tabular}

Tabel 4 menjelaskan bahwa mahasiswa dengan orang tua bekerja sebagai tenaga kesehatan memiliki pengetahuan tentang POACE hampir 3 kali lebih baik 
dibandingkan dengan mahasiswa yang orang tua memiliki profesi non tenaga kesehatan. Mahasiswa yang merasa puas terhadap perkuliahan di FKM Unsrat memiliki pengetahuan tentang POACE 2 kali lebih baik dibandingkan mahasiswa yang kurang puas. Sebaliknya, keinginan untuk bekerja sebagai Kepala dinas kesehatan negatif terhadap pengetahuan manajemen. Mahasiswa yang ingin menjadi Kepala Dinas Kesehatan 50\% berisiko memiliki pengetahuan yang lebih buruk dibandingkan mahasiswa yang ingin bekerja dengan profesi lain.

Tabel 4. Determinan pengetahuan fungsi manajemen

\begin{tabular}{|c|c|c|c|}
\hline Variabel & $\begin{array}{c}\text { Model 1 } \\
\text { OR } \\
(95 \% \mathrm{CI}) \\
\end{array}$ & $\begin{array}{c}\text { Model } 2 \\
\text { OR } \\
(95 \% \mathrm{CI}) \\
\end{array}$ & $\begin{array}{c}\text { Model 3 } \\
\text { OR } \\
(95 \% \mathrm{CI}) \\
\end{array}$ \\
\hline $\begin{array}{l}\text { Bidang } \\
\text { minat }\end{array}$ & & & \\
\hline $\begin{array}{l}\text { AKK } \\
\text { Non AKK } \\
\text { Jenis } \\
\text { kelamin }\end{array}$ & $2,1(1,0-4,2)$ & $1,6(0,8-3,3)$ & - \\
\hline $\begin{array}{l}\text { Laki-laki } \\
\text { Perempuan } \\
\text { Pekerjaan or }\end{array}$ & $\begin{array}{l}0,6(0,3-1,1) \\
\text { g tua }\end{array}$ & - & - \\
\hline $\begin{array}{l}\text { Tenaga } \\
\text { kesehatan } \\
\text { Non tenaga } \\
\text { kesehatan } \\
\text { Pilihan masu }\end{array}$ & $4,3(1,4-13,0)$ & $3,0(1,1-3,3)$ & $2,9(1,0-8,4)^{*}$ \\
\hline $\begin{array}{l}\text { Pilihan } \\
\text { pertama } \\
\text { Lainnya } \\
\text { Jabatan yang }\end{array}$ & harapkan & - & - \\
\hline $\begin{array}{l}\text { Kepala dinas } \\
\text { Lainnya } \\
\text { Jabatan yang }\end{array}$ & $\begin{array}{l}0,4(0,2-0,8) \\
\text { harapkan }\end{array}$ & $0,5(0,3-0,9)$ & $0,5(0,3-0,9)^{*}$ \\
\hline $\begin{array}{l}\text { Kepala } \\
\text { puskesmas } \\
\text { Lainnya }\end{array}$ & $0,5(0,2-1,1)$ & - & - \\
\hline Kepuasan ku & h di FKM & & \\
\hline $\begin{array}{l}\text { Puas } \\
\text { Kurang puas } \\
\text { Kunjungan la }\end{array}$ & $\begin{array}{l}2,2(1,2-4,1) \\
\text { angan }\end{array}$ & $2,0(1,1-3,6)$ & $2,1(1,2-3,7)^{*}$ \\
\hline $\begin{array}{l}\text { Banyak } \\
\text { Kurang }\end{array}$ & $0,6(0,3-1,1)$ & - & - \\
\hline Kuliah tatap & uka & & \\
\hline $\begin{array}{l}\text { Banyak } \\
\text { Kurang }\end{array}$ & $0,6(0,3-1,2)$ & - & - \\
\hline
\end{tabular}

\section{BAHASAN}

Pengetahuan manajemen mahasiswa. Pengetahuan mahasiswa tentang fungsi manajemen masih kurang, sebanyak 51,46\% mahasiswa memiliki pengetahuan di bawah nilai rata-rata. Pengetahuan mahasiswa tentang masing-masing fungsi manajemen bervariasi. Hasil tersebut mengindikasikan bahwa pengajaran tentang fungsi manajemen belum optimal dan belum mencakup aplikasi yang lebih luas terkait masing-masing fungsi perencanaan, pengorganisasian, pelaksanaan, pengawasan dan evaluasi.
Perencanaan adalah kemampuan merumuskan tujuan dan merancang cara untuk mencapai tujuan tersebut (6). Perencanaan adalah langkah awal dalam proses manajemen dan menjadi domain penting dalam kompetensi manajemen (2,6,13-15). Beberapa penelitian menyimpulkan bahwa terdapat gap antara pengetahuan tentang fungsi perencanaan yang dimiliki dan diharapkan $(15,20)$.

Bentuk fungsi pengorganisasian yang diuraikan dalam kuesioner adalah tentang penguraian dan pembagian tugas serta penempatan orang pada posisi yang tepat. Hal tersebut penting namun belum diaplikasikan secara nyata. Negara-negara berkembang mengalami kekurangan tenaga kesehatan berkompeten yang ditempatkan sesuai dengan bidang keahlian (1). Kompetensi pengorganisasian rendah diduga menjadi salah satu penyebab.

Fungsi pelaksanaan merupakan salah satu domain utama kompetensi manajemen (20). Pertanyaan yang disusun di kuesioner adalah tentang bentuk-bentuk dari kegiatan fungsi pelaksanaan terkait pelayanan. Mahasiswa belum mampu membedakan bentuk kegiatan tersebut diasumsikan karena keterbatasan pengalaman langsung di lapangan yang dapat memudahkan mahasiswa untuk mengalami dan memahami bentuk konkrit pelaksanaan manajemen.

Bentuk-bentuk aplikasi dari fungsi pengawasan yang disampaikan melalui kuesioner adalah mengenai supervisi kegiatan. Supervisi dinilai penting namun penerapan masih belum efektif meningkatkan kinerja, motivasi dan pelayanan (21,22). Pemahaman yang benar tentang implementasi supervisi yang tepat perlu ditingkatkan untuk hasil yang lebih maksimal. Fungsi evaluasi juga merupakan kompetensi penting yang wajib dimiliki oleh manajer. Namun, masih terdapat gap yang siginfikan antara pengetahuan tentang fungsi evaluasi yang dimiliki dan diharapkan $(2,15)$.

Kelemahan pengetahuan di domain manajemen adalah akibat pendidikan dan pelatihan terkait fungsi-fungsi manajemen tersebut kurang efektif (15). Manajer perlu mempunyai beragam kompetensi manajemen agar dapat melaksanakan program secara efektif dan efisien (6). Diperlukan pengetahuan yang seimbang tentang keseluruah fungsi manajemen POACE.

Sesuai taksonomi Bloom, pengetahuan mahasiswa tentang fungsi manajemen pada umumnya masih terbatas pada tahap mengingat atau tahu dan masih kurang memahami penerapan fungsi manajemen. Pengajaran tentang manajemen perlu ditingkatkan hingga lebih tinggi yaitu memahami, menerapkan, menganalisis, mengevaluasi dan mencipta (23). 
Pengetahuan manajemen mahasiswa bidang minat administrasi kebijakan kesehatan lebih baik daripada bidang minat lain, dengan 58,33\% mahasiswa berpengetahuan baik. Hal ini diduga karena mereka lebih banyak menerima pengajaran terkait manajemen.

Pengaruh karakteristik individu terhadap pengetahuan manajemen. Pendidikan dilakukan dengan tujuan meningkatkan pengetahuan dan kompetensi para peserta didik. Manajemen pendidikan yang baik akan mampu menghasilkan penyelenggaraan pendidikan yang baik pula. Kepuasan merupakan salah satu tolak ukur pelayanan. Kualitas pelayanan yang baik memberikan pengaruh positif terhadap kepuasan mahasiswa $(24,25)$.

Kepuasan terhadap perkuliahan mencerminkan pelayanan yang diberikan oleh kampus. Penelitian ini menemukan bahwa masih banyak mahasiswa yang merasa kurang puas, yaitu sebanyak 46,12\% (Tabel 3), oleh karena itu pelayanan masih perlu ditingkatkan.

Kepuasan terhadap perkuliahan meningkatkan prestasi akademik siswa (26). Tabel 2 menunjukkan bahwa mahasiswa yang merasa puas terhadap perkuliahan memiliki pengetahuan tentang fungsi manajemen 2 kali lebih baik dibandingkan mahasiswa yang kurang puas.

Aspek terpenting penentu kepuasan siswa adalah kegiatan belajar mengajar (27). Beberapa penelitian terdahulu juga membuktikan hal yang sama bahwa kepuasan siswa terhadap layanan pendidikan dan kualitas universitas dinilai dari kepuasan terhadap aspek akademis $(25,28,29)$. Kegiatan belajar mengajar diselenggarakan berdasarkan kurikulum yang disusun oleh fakultas (30). Kurikulum yang menunjang sangat memengaruhi kompetensi mahasiswa. Keterbatasan perhatian terhadap pendidikan manajemen dalam kurikulum pendidikan dianggap merupakan penyebab kompetensi manajemen rendah $(17,18,19)$. Fakultas melalui bidang akademik diharapkan mampu merancang desain pembelajaran yang tepat dan fleksibel (25).

Isi dari pengajaran yang akan diberikan juga sangat penting dalam penyusunan kurikulum (31,32). Isi pengajaran sebaiknya disesuaikan dengan tujuan pembelajaran dan standar kompetensi lulusan yang hendak dicapai, sehingga bisa ditetapkan metode pembelajaran maupun cara penilaian yang tepat (33). Kurikulum pendidikan perlu direformasi sehingga berorientasi pada standar kompetensi manajemen berbasis POACE dan lebih bersifat operasional sehingga mahasiswa lebih memahami tentang praktik-praktik manajerial.

Faktor individu lain yang berpengaruh terhadap pengetahuan manajemen mahasiswa adalah pekerjaan orang tua. Mahasiswa yang memiliki orang tua bekerja sebagai tenaga kesehatan memiliki pengetahuan manajemen hampir 4 kali lebih baik dibandingkan yang tidak. Lingkungan yang mendukung secara sosial dan emosional termasuk dukungan dari keluarga berdampak positif dalam meningkatkan efektivitas proses pembelajaran (34).

Peran orang tua sangat besar terhadap prestasi belajar anak. Mayoritas anak menjadikan orang tua sebagai role model, sehingga termotivasi lebih menekuni pendidikan karena ingin menjadi seperti orang tua, sehingga anak melihat langsung praktik manajemen. Anak melihat dan mengalami langsung praktik manajerial melalui kehidupan dan pekerjaan orang tua mereka sehari-hari. Seharusnya proses pembelajaran lebih berpengaruh dalam meningkatkan pengetahuan mahasiswa dibandingkan pekerjaan orang tua, oleh karena itu evaluasi dan peningkatan kualitas pembelajaran sangat diperlukan.

Berbeda dengan kepuasan terhadap perkuliahan dan pekerjaan orang tua yang berpengaruh meningkatkan pengetahuan mahasiswa, pemilihan jabatan yang diinginkan dalam pekerjaan di masa depan berpengaruh sebaliknya. Mahasiswa yang memiliki motivasi ingin menjadi kepala dinas 50\% berisiko memiliki pengetahuan yang lebih buruk, namun ada dugaan bahwa mahasiswa yang tertarik menjadi kepala dinas bukan mahasiswa yang selektif atau memiliki pengetahuan yang baik. Mahasiswa yang lebih baik pengetahuan manajemen lebih tertarik bekerja di tempat lain selain dinas kesehatan. Penelitian Barzdins menemukan mahasiswa yang ingin bekerja di klinik pribadi atau swasta memiliki pengetahuan manajemen yang lebih baik (19). Ketidaksesuaian antara kebutuhan mahasiswa dan sistem pendidikan memengaruhi motivasi mahasiwa, karena itu kurikulum dan strategi pembelajaran harus ditingkatkan untuk mempersiapkan calon tenaga kesehatan yang bermutu.

Pengaruh proses pembelajaran terhadap pengetahuan manajemen. Proses pembelajaran terdiri dari perkuliahan tatap muka berupa proses belajar mengajar di dalam kelas serta praktik belajar lapangan berupa kegiatan magang, praktik belajar lapangan (PBL), kuliah kerja nyata (KKN) dan kunjungan ke lapangan sebagai penugasan dari dosen untuk memperoleh data tertentu. 
Kuliah tatap muka dan jumlah kunjungan lapangan tidak berpengaruh terhadap pengetahuan manajemen mahasiswa. Padahal secara umum pelaksanaan kuliah terkait manajemen kesehatan, pemberian tugas-tugas, penguasaan dosen manajemen terhadap materi yang diajarkan maksimal kecuali media/alat penunjang kegiatan belajar mengajar yang masih sedikit atau kurang. Diduga karena dalam kuliah tatap muka lebih banyak mengajarkan pengetahuan yang bersifat teoritis sedangkan kuesioner berisi bentuk-bentuk praktik langsung manajemen di lapangan.

Pengalaman belajar lapangan diharapkan mampu meningkatkan pengetahuan mahasiswa tentang praktik manajemen dibandingkan kuliah tatap muka. Filerman menyatakan bahwa kursus atau pelajaran dapat mengembangkan pengetahuan dan keterampilan namun tidak mencapai tingkat pelaksanaan jika tanpa pengalaman di lapangan. Kompetensi manajemen akan lebih efektif jika dipelajari melalui pelatihan langsung di tempat kerja (1). Pengalaman belajar manajemen berbasis tempat kerja lebih efektif dalam mengubah pengetahuan menjadi tindakan atau praktik (35). Namun hasil penelitian ini menunjukkan hasil yang berbeda, yaitu banyaknya kegiatan praktik lapangan belum mampu meningkatkan pengetahuan manaje- men mahasiswa. Kunjungan lapangan masih kurang dan bervariasi pada setiap mahasiswa.

\section{SIMPULAN}

Mahasiswa memperlihatkan variasi dalam hal pengetahuan mereka tentang bentuk-bentuk praktik manajemen, meliputi perencanaan, pengorganisasian, pelaksanaan, pengawasan dan evaluasi. Pengetahuan fungsi manajemen memiliki hubungan positif dengan kepuasan mahasiswa terhadap proses perkuliahan, paparan terhadap orang tua yang bekerja sebagai tenaga kesehatan dan memiliki hubungan negatif dengan keinginan bekerja di dinas kesehatan. Mahasiswa yang berkeinginan bekerja di dinas kesehatan justru memiliki pengetahuan manajerial yang lebih buruk daripada yang tidak ingin bekerja di dinas kesehatan. Kuliah tatap muka dan pengalaman belajar lapangan tidak memiliki hubungan dengan pengetahuan manajemen mahasiswa.

Perbaikan dalam pengelolaan kunjungan ke dinas kesehatan kiranya dapat mendorong penguasaan fungsi manajemen mahasiswa. Penelitian lanjutan diharapkan dapat mengkaji lebih dalam tentang proses belajar mengajar di fakultas kesehatan masyarakat terkait faktor-faktor yang memengaruhi proses belajar mengajar dan bentuk pembelajaran yang tepat dalam meningkatkan pengetahuan manajemen mahasiswa.

\section{Abstrak}

Tujuan: Penelitian ini bertujuan menjawab pertanyaan apakah mahasiswa fakultas kesehatan masyarakat yang di masa akan datang memiliki pendidikan yang memadai dalam hal pengetahuan dan kompetensi manajerial agar mereka bisa bekerja menjadi manajer program-program public health di dinas kesehatan, tempat mereka akan paling besar kemungkinan bekerja. Metode: Penelitian observasional ini menggunakan rancangan cross sectional study. Subjek penelitian adalah mahasiswa semester akhir Fakultas Kesehatan Masyarakat Universitas Sam Ratulangi. Alat ukur menggunakan kuesioner. Variabel bebas adalah karakteristik individu dan proses pembelajaran, variabel terikat adalah pengetahuan mahasiswa tentang manajemen. Analisis data menggunakan analisis univariat, bivariat dengan chi square dan multivariat dengan regresi logistik. Hasil: Responden berjumlah 206 mahasiswa (61,13\%). Mahasiswa yang memiliki pengetahuan baik tentang manajemen sebanyak 48,54\%. Determinan di tingkat individu pada pengetahuan manajemen mahasiswa adalah kepuasaan mahasiswa terhadap perkuliahan (OR: 2,1), pekerjaan orang tua (OR: 2,9) serta jabatan yang diinginkan (OR: 0,5). Kuliah tatap muka dan pengalaman belajar lapangan tidak berhubungan dengan pengetahuan manajemen. Simpulan: Mereka yang ingin berkarir di dinas justru memiliki pengetahuan manajerial yang lebih buruk daripada yang ingin berkarir di luar dinas kesehatan. Temuan yang bertolak belakang dalam hal kesesuaian karir di dinas kesehatan dan pengetahuan manajerial mereka menunjukkan arti penting mengenalkan dinas kesehatan, pengetahuan dan ketrampilan manajemen diajarkan dan dilatih di perguruan tinggi agar dinas kesehatan memperoleh lulusan yang sesuai dengan kebutuhan mereka.

Kata kunci: kompetensi manajemen; fungsi manajemen program; magang dinas keseahtan; pendidikan manajemen program di perguruan tinggi kesehatan masyarakat. 


\section{PUSTAKA}

1. Filerman G. Closing The Management Competence Gap. Hum Resour Health. 2003;3:1-3.

2. Mohd-Shamsudin F, Chuttipattana N. Determinants of managerial competencies for primary care managers in Southern Thailand. Journal of health organization and management. 2012 May 18;26(2):258-80.

3. Isouard G. Biosafety \& Health Education An Urgent Need for Investment in Health Management Education. 2012;1(2):1-2.

4. Haddad S, Fournier P, Machouf N, Yatara F. What does quality mean to lay people? Community perceptions of primary health care services in Guinea. Social Science \& Medicine. 1998 Aug 1;47(3):381-94.

5. Al-Ahmadi H, Roland M. Quality of primary health care in Saudi Arabia: a comprehensive review. International Journal for Quality in Health Care. 2005 May 9;17(4):331-46.

6. Pillay R. Managerial competencies of hospital managers in South Africa: a survey of managers in the public and private sectors. Human Resources for Health. 2008 Dec;6(1):4.

7. Heywood P, Choi Y. Health system performance at the district level in Indonesia after decentralization. BMC international health and human rights. 2010 Dec;10(1):3.

8. Supardi. Kemampuan Manajerial Kepala Puskesmas dalam Meningkatkan Mutu Pelayanan di Puskesmas Kota Mataram. Tesis Progr Stud Ilmu Kesehat Masy UGM. 2008.

9. Briggs D, Cruickshank M, Paliadelis P. Health managers and health reform. Journal of Management \& Organization. 2012 Sep;18(5):641-58.

10. Kementerian Kesehatan. Peraturan Menteri Kesehatan Republik Indonesia Nomor 75 Tahun 2014 tentang Pusat Kesehatan Masyarakat. Jakarta; 2014.

11. Anderson P. The Managerial Roles of Community Collage Chief Academic Officers. 2002.

12. Sulaeman ES. Manajemen Kesehatan Teori dan Praktik di Puskesmas. Cetakan Kedua. Yogyakarta: Gadjah Mada University Press; 2011.

13. Santrić Milicevic MM, Bjegovic-Mikanovic VM, Terzic-Supić ZJ, Vasic V. Competencies gap of management teams in primary health care. European journal of public health. 2010 Mar 9;21(2):247-53.

14. Mansour M, Mansour JB, El Swesy AH. Scaling up proven public health interventions through a locally owned and sustained leadership development programme in rural Upper Egypt. Human Resources for Health. 2010 Dec;8(1):1.

15. Stergiopoulos V, Lieff S, Razack S, Lee AC, Maniate JM, Hyde S, Taber S, Frank JR. Canadian residents' perceived manager training needs. Medical teacher. 2010 Nov 1;32(11):e479-85.

16. Sudha T. Total Quality Management in Higher Education Institutions. 2013;2(6):121-132.

17. Brouns JW, Berkenbosch L, Ploemen-Suijker FD, Heyligers I, Busari JO. Medical residents perceptions of the need for management education in the postgraduate curriculum: a preliminary study. Int J Med Educ. 2010 Dec 11;1:76-82.
18. Abbas MR, Quince TA, Wood DF, Benson JA. Attitudes of medical students to medical leadership and management: a systematic review to inform curriculum development. BMC medical education. 2011 Dec;11(1):93.

19. Barzdins J, Barzdins A. A pilot study on self-perceived need for management training among medical students in Latvia. International Journal of Medical Education. 2013 Jan 1;4:59.

20. Slipicevic O, Masic I. Management knowledge and skills required in the health care system of the federation Bosnia and Herzegovina. Materia socio-medica. 2012;24(2):106.

21. Bosch-Capblanch $X$, Liaqat $S$, Garner $P$. Managerial supervision to improve primary health care in low-and middle-income countries. The Cochrane Library. 2011 Jan 1.

22. Bosch-Capblanch X, Garner P. Primary health care supervision in developing countries. Tropical medicine \& international health. 2008 Mar 1;13(3):369-83.

23. Krathwohl DR. A Revision of Bloom's Taxonomy: An Overview. Theory Pract. 2002;41(4).

24. Prasetyaningrum ID. Analisis Pengaruh Pembelajaran dan Kualitas Pelayanan terhadap Kepuasan Mahasiswa dan Loyalitas Mahasiswa (Studi Kasus pada Undaris Ungaran). Tesis. 2009.

25. Ali F, Zhou Y, Hussain K, Nair PK, Ragavan NA. Does higher education service quality effect student satisfaction, image and loyalty? A study of international students in Malaysian public universities. Quality Assurance in Education. 2016 Feb 1;24(1):70-94.

26. Samdal O, Wold B, Bronis M. Relationship between students' perceptions of school environment, their satisfaction with school and perceived academic achievement: An international study. School Effectiveness and School Improvement. 1999 Sep 1;10(3):296-320.

27. Douglas J, Douglas A, Barnes B. Measuring student satisfaction at a UK university. Quality assurance in education. $2006 \mathrm{Jul}$ 1;14(3):251-67.

28. Joseph M, Joseph B. Service quality in education: a student perspective. Quality assurance in education. 1997 Mar 1;5(1):15-21.

29. Price IF, Matzdorf F, Smith L, Agahi H. The impact of facilities on student choice of university. Facilities. 2003 Oct 1;21(10):212-22.

30. Kementerian Pendidikan. Keputusan Menteri Pendidikan Nasional Republik Indonesia Nomor 232/U/2000 tentang Pedoman Penyusunan Kurikulum Pendidikan Tinggi dan Penilaian Hasil Belajar Mahasiswa. Jakarta; 2000:1-8.

31. Hill FM. Managing service quality in higher education: the role of the student as primary consumer. Quality assurance in education. 1995 Sep 1;3(3):10-21.

32. Athiyaman A. Linking student satisfaction and service quality perceptions: the case of university education. European journal of marketing. 1997 Aug 1;31(7):528-40.

33. Yaumi M. Prinsip-Prinsip Desain Pembelajaran Disesuaikan dengan Kurikulum 2013. 2nd ed. Jakarta: Kencana; 2014.

34. Hill Y, Lomas L, MacGregor J. Students' perceptions of quality in higher education. Quality assurance in education. 2003 Mar 1;11(1):15-20.

35. Briggs D. Developing Health Managers for Effective Health Care Delivery. Present the 1st Int Conf Heal Serv Deliv Manag Thail Oct 2009. 
